\title{
Acts Freely on Prime and semi prime $\Gamma$-near Rings
}

\author{
Afrah M Ibraheem , Ahlam J. Lazem \\ Dep. of Mathematics, College of Education, Al-Mustansiriya Univ., Baghdad, Iraq
}

\begin{abstract}
Let $M$ be a $\Gamma$-near ring. An element $a \in M$ is called a dependent element on a mapping $f$ if
$f(x) \alpha a=a \alpha x$ for all $x \in M, \alpha \in \Gamma$. In this paper we study and investigate concerning dependent elements of $M$ by certain mappings on prime and semi prime $\Gamma$-near rings using certain assumption $(A)$, and also we study the generalized $\Gamma$-derivation $F$ of $\Gamma$-near ring $M$ and $\Gamma$-derivations $D$ which are free action.
\end{abstract}

KeyWords: $\Gamma$-near ring, generalized $\Gamma$-derivation, reverse centralizer, dependent element, free action.

\section{Introduction And Preminiries}

Some researchers have studied the notion of free action. Laradji and Thaheem in [1] initiated the study of dependent elements of endemorphism of semiprime ring. F.J.Murray and J.Von Neuman in [2], introduced the notions of dependent elements and free action. In [8],Vukman and Ireana investigate some properties of dependent elements of derivations, generalized derivations and automorphisms of prime and semiprime rings. M.S.Samman and M. Anwar in [3] have studied some properties of dependent elements of left centralizers. Vukman and Kosi-UIbI in [7] and Vukman in [4] and [5] on dependant elements of mappings of semiprime rings, Vukman and Kusi-UIbI in [6] have studied centralizers in general from work of semiprime rings.

In this paper we investigate some mappings related to centralizer, reverse-centralizer, $\Gamma$-derivations and generalized $\Gamma$-derivations are free actions on prime and semi prime $\Gamma$-near rings.

Throughout $M$ will represent an associative $\Gamma$-near ring with center $Z(M)$ the commutator $[\mathrm{x}, \mathrm{y}]_{\alpha}$ will denoted by $\mathrm{x} \alpha \mathrm{y}-\mathrm{y} \alpha \mathrm{x}$ for all $\mathrm{x}, \mathrm{y} \in \mathrm{M}$ and $\alpha \in \Gamma$, and we use the identities below

$[\mathrm{x} \beta \mathrm{y}, \mathrm{z}]_{\alpha}=\mathrm{x} \beta[\mathrm{y}, \mathrm{z}]_{\alpha}+[\mathrm{x}, \mathrm{z}]_{\alpha} \beta \mathrm{y}+\mathrm{x} \beta \mathrm{z} \alpha \mathrm{y}-\mathrm{x} \alpha \mathrm{z} \beta \mathrm{y}$ and

$[\mathrm{x}, \mathrm{y} \beta \mathrm{z}]_{\alpha}=\mathrm{y} \beta[\mathrm{x}, \mathrm{z}]_{\alpha}+[\mathrm{x}, \mathrm{y}]_{\alpha} \beta \mathrm{z}+\mathrm{y} \beta \mathrm{x} \alpha \mathrm{z}-\mathrm{y} \alpha \mathrm{x} \beta \mathrm{z}$, for all $\mathrm{x}, \mathrm{y}, \mathrm{z} \in \mathrm{M}$ and $\alpha, \beta \in \Gamma$.

We shall take an assumption (A)... x $\alpha y \beta z=x \beta y \alpha z$, for all $x, y, z \in M$ and $\alpha, \beta \in \Gamma$.

A $\Gamma$-near ring $\mathrm{M}$ is a triple $(\mathrm{M},+, \Gamma)$ where

(i) $(\mathrm{M},+)$ is a group (not necessarily abelian).

(ii) $\Gamma$ is a non empty set of binary operations on $\mathrm{M}$-such that for each $\alpha \in \Gamma,(\mathrm{M},+, \alpha)$ is a near ring.

(iii) $\mathrm{x} \alpha(\mathrm{y} \beta \mathrm{z})=(\mathrm{x} \alpha \mathrm{y}) \beta \mathrm{z}$, for all $\mathrm{x}, \mathrm{y}, \mathrm{z} \in \mathrm{M}$ and $\alpha, \beta \in \Gamma$.

$\mathrm{M}$ is said to be prime $\Gamma$-near ring if $\mathrm{x} \Gamma \mathrm{M} \Gamma \mathrm{y}=(0)$ for all $\mathrm{x}, \mathrm{y} \in \mathrm{M}$ implies $\mathrm{x}=0$ or $\mathrm{y}=0$ and semi prime $\Gamma$-near ring if $\mathrm{x} \Gamma \mathrm{M} \Gamma \mathrm{x}=(0)$ for all $\mathrm{x} \in \mathrm{M}$ implies $\mathrm{x}=0 . \mathrm{A} \Gamma$-near ring $\mathrm{M}$ is said to be 2-torsion free whenever $2 \mathrm{x}=0$, for all $\mathrm{x} \in \mathrm{M}$, then $\mathrm{x}=0$.A $\Gamma$-derivation on $\mathrm{M}$ is defined to be an additive endomorphism $\mathrm{D}$ of $\mathrm{M}$ satisfying the product rule $\mathrm{D}(\mathrm{x} \alpha \mathrm{y})=\mathrm{D}(\mathrm{x}) \alpha \mathrm{y}+\mathrm{x} \alpha \mathrm{D}(\mathrm{y})$ or equivalently $\mathrm{D}(\mathrm{x} \alpha \mathrm{y})=\mathrm{x} \alpha \mathrm{D}(\mathrm{y})+\mathrm{D}(\mathrm{x}) \alpha \mathrm{y}$, for all $\mathrm{x}, \mathrm{y} \in \mathrm{M}$ and $\alpha \in \Gamma$.An additive mapping F: $\mathrm{M} \rightarrow \mathrm{M}$ is called generalized $\Gamma$-derivation if there exists $\Gamma$-derivation $\mathrm{D}$ of $\mathrm{M}$ such that $\mathrm{F}(\mathrm{x} \alpha \mathrm{y})=\mathrm{F}(\mathrm{x}) \alpha \mathrm{y}+\mathrm{x} \alpha \mathrm{D}(\mathrm{y})$. An additive mapping $\mathrm{T}: \mathrm{M} \rightarrow \mathrm{M}$ is called left (resp.right) centralizer if $\mathrm{T}(\mathrm{x} \alpha \mathrm{y})=$ $\mathrm{T}(\mathrm{x}) \alpha \mathrm{y},(\mathrm{T}(\mathrm{x} \alpha \mathrm{y})=\mathrm{x} \alpha \mathrm{T}(\mathrm{y}))$, for all $\mathrm{x}, \mathrm{y} \in \mathrm{M}$ and $\alpha \in \Gamma$. If $\mathrm{T}$ is a both left as well right centralizer then $\mathrm{T}$ is centralizer for all $\mathrm{x}, \mathrm{y} \in \mathrm{M}$ and $\alpha \in \Gamma$, and $\mathrm{T}$ is called left (resp. right) reverse centralizer of $\mathrm{M}$ if $\quad T(x \alpha y)=$ $\mathrm{T}(\mathrm{y}) \alpha \mathrm{x},(\mathrm{T}(\mathrm{x} \alpha \mathrm{y})=\mathrm{y} \alpha \mathrm{T}(\mathrm{x}))$ hold for all $\mathrm{x}, \mathrm{y} \in \mathrm{M}$ and $\alpha \in \Gamma$. If $\mathrm{T}$ is both left as well right reverse-centralizer, then $T$ is a reverse-centralizer. An element $a \in M$ is called a dependent element of mapping $\quad f: M \rightarrow M$ if $\mathrm{f}(\mathrm{x}) \alpha \mathrm{a}=\mathrm{a} \alpha \mathrm{x}$ holds for all $\mathrm{x} \in \mathrm{M}$ and $\alpha \in \Gamma$.A mapping $\mathrm{f}: \mathrm{M} \rightarrow \mathrm{M}$ is said to be free action if the only depend element of $\mathrm{f}$ is zero. The symbol $\mathrm{D} *(\mathrm{f})$ is denoted to the collection of all dependent elements.

\section{Results}

We consider $\mathrm{M}$ in all our results satisfying the assumption (A).

\section{Theorem (2.1):}

Let $\mathrm{M}$ be a prime $\Gamma$-near ring with a non zero $\Gamma$-derivation $\mathrm{D}$, then $\mathrm{D}$ is a free action.

\section{Theorem (2.2):}

Let $\mathrm{M}$ be a semi prime $\Gamma$-near ring , and $\mathrm{F}$ be a non zero generalized $\Gamma$-derivation associated with a $\Gamma$-derivation $\mathrm{D}$, then $\mathrm{F}$ is a free action. 
Proof:

For all $\mathrm{x} \in \mathrm{M}, \mathrm{a} \in \mathrm{M}$ and $\alpha \in \Gamma$, we have the relation

$\mathrm{F}(\mathrm{x}) \alpha \mathrm{a}=\mathrm{a} \alpha \mathrm{x}$

Putting $\mathrm{x} \beta \mathrm{y}$ for $\mathrm{x}$, and using (1), we get

$\mathrm{F}(\mathrm{x}) \beta \mathrm{y} \alpha \mathrm{a}+(\mathrm{x} \alpha \mathrm{a}-\mathrm{a} \alpha \mathrm{x}) \beta \mathrm{y}=0$, for all $\mathrm{x}, \mathrm{y} \in \mathrm{M}$ and $\alpha, \beta \in \Gamma$

...(2) Putting

$\mathrm{y} \delta \mathrm{z}$ for $\mathrm{y}$ in (2), and other hand right multiplication of (2) by z, and subtraction two equations, we obtain

$\mathrm{F}(\mathrm{x}) \beta \mathrm{y} \delta(\mathrm{z} \alpha \mathrm{a}-\mathrm{a} \alpha \mathrm{z})=0$,for all $\mathrm{x}, \mathrm{y}, \mathrm{z} \in \mathrm{M}$ and $\alpha, \beta, \delta \in \Gamma$

Replacing y by a $\lambda y$ in (3), and using (1),we obtain

$\mathrm{a} \beta \mathrm{x} \lambda \mathrm{y} \delta(\mathrm{z} \alpha \mathrm{a}-\mathrm{a} \alpha \mathrm{z})=0$

Replacing $\mathrm{x}$ by $\mathrm{z} \alpha \mathrm{x}$ in (4), and other hand left multiplication of (4) by $\mathrm{z}$, and subtracting two equations, we obtain:

$(\mathrm{z} \alpha \mathrm{a}-\mathrm{a} \alpha \mathrm{z}) \beta \mathrm{x} \lambda \mathrm{y} \delta(\mathrm{z} \alpha \mathrm{a}-\mathrm{a} \alpha \mathrm{z})=0$,for all $\mathrm{x}, \mathrm{y}, \mathrm{z} \in \mathrm{M}$ and $\alpha, \beta, \delta, \lambda \in \Gamma$

Replacing $\mathrm{x} \lambda \mathrm{y}$ by $\mathrm{r}$ in (5), we obtain

$(\mathrm{z} \alpha \mathrm{a}-\mathrm{a} \alpha \mathrm{z}) \beta \mathrm{r} \delta(\mathrm{z} \alpha \mathrm{a}-\mathrm{a} \alpha \mathrm{z})=0$,for all $\mathrm{z}, \mathrm{r} \in \mathrm{M}$ and $\alpha, \beta, \delta \in \Gamma$

Since $M$ is semi prime, we get

$(\mathrm{z} \alpha \mathrm{a}-\mathrm{a} \alpha \mathrm{z})=0$

Substitution (7) in (2)for all $\mathrm{z} \in \mathrm{M}$, and replacing y by a $\delta y$ using (1), we get

$\mathrm{a} \beta \mathrm{x} \delta \mathrm{y} \alpha \mathrm{a}=0$

Putting $\mathrm{z}$ for $\mathrm{x} \delta \mathrm{y}$ in (8), we get:

$\mathrm{a} \beta z \alpha \mathrm{a}=0$, for all $\mathrm{z} \in \mathrm{M}$, and $\alpha, \beta \in \Gamma$.

Since $\mathrm{M}$ is semi prime, we get $\mathrm{a}=0$.This completes the proof.

Theorem (2.3):

Let $\mathrm{M}$ be a prime $\Gamma$-near ring and $\mathrm{F}$ be a generalized $\Gamma$-derivation on $\mathrm{M}$ associated with a non zero

$\Gamma-$ derivation $D$. If $a \in M$, $a$ is dependent element of $F$, then $a \in Z(M)$.

Proof:

Since a an element dependent on $\mathrm{F}$, therefore

$\mathrm{F}(\mathrm{x}) \alpha \mathrm{a}=\mathrm{a} \alpha \mathrm{x}$, for all $\mathrm{x} \in \mathrm{M}$ and $\alpha \in \Gamma$

Replacing $\mathrm{x}$ by $\mathrm{x} \beta \mathrm{y}$ in (1) and using (1), we get

$(\mathrm{F}(\mathrm{x}) \alpha \mathrm{a}-\mathrm{x} \alpha \mathrm{a}) \beta \mathrm{y}=\mathrm{D}(\mathrm{x}) \beta \mathrm{y} \alpha \mathrm{a}$, for all $\mathrm{x}, \mathrm{y} \in \mathrm{M}$ and $\alpha, \beta \in \Gamma$

Right multiplication (2) by z, other hand replacing y by y $\delta \mathrm{z}$ in (2), and subtracting two equations , we get

$\mathrm{D}(\mathrm{x}) \beta \mathrm{y} \delta[\mathrm{a}, \mathrm{z}]_{\alpha}=0$, for all $\mathrm{x}, \mathrm{y}, \mathrm{z} \in \mathrm{M}$ and $\alpha, \beta, \delta \in \Gamma$

Since $M$ is a prime and $D \neq 0$, we obtain

$[\mathrm{a}, \mathrm{z}]_{\alpha}=0$ that means $\mathrm{a} \in \mathrm{Z}(\mathrm{M})$, for all $\mathrm{z} \in \mathrm{M}, \alpha \in \Gamma$.This completes the proof.

Corollary (2.4):

Let $\mathrm{M}$ be a prime $\Gamma$-near ring, and let $\mathrm{a}, \mathrm{b} \in \mathrm{M}$ be a fixed elements. Suppose that $\mathrm{c} \in \mathrm{M}$ is dependent element of $F(x)=a \alpha x+x \alpha b$. Then $c \in Z(M)$.

Proof:

For all $\mathrm{x} \in \mathrm{M}$ and $\alpha \in \Gamma$, we obtain:

$\mathrm{F}(\mathrm{x})=\mathrm{a} \alpha \mathrm{x}$

Replacing $\mathrm{x}$ by $\mathrm{x} \beta \mathrm{y}$ in (1), we get:

$\mathrm{F}(\mathrm{x} \beta \mathrm{y})=(\mathrm{a} \alpha \mathrm{x}+\mathrm{x} \alpha \mathrm{b}) \beta \mathrm{y}+\mathrm{x} \beta[\mathrm{y}, \mathrm{b}]_{\alpha}$, for all $\mathrm{x}, \mathrm{y} \in \mathrm{M}$ and $\alpha, \beta \in \Gamma$

Replacing $[\mathrm{y}, \mathrm{b}]_{\alpha}$ by $\mathrm{D}(\mathrm{y})$ in (2) and using (1), we get:

$\mathrm{F}(\mathrm{x} \beta \mathrm{y})=\mathrm{F}(\mathrm{x}) \beta \mathrm{y}+\mathrm{x} \beta \mathrm{D}(\mathrm{y})$, for all $\mathrm{x}, \mathrm{y} \in \mathrm{M}$ and $\beta \in \Gamma$

This mean $\mathrm{F}$ is a generalized $\Gamma$-derivation where it follows according the theorem (2.3), $\mathrm{c} \in \mathrm{Z}(\mathrm{M})$.

\section{Theorem (2.5):}

Let $\mathrm{M}$ be a prime $\Gamma$-near ring, and let $\mathrm{a}, \mathrm{b} \in \mathrm{M}$ be fixed elements. Suppose that $\mathrm{c} \in \mathrm{M}$ is dependent element on the mapping $\psi(x)=a \alpha x \beta b$, then $a \alpha c \in Z(M)$ or $b \alpha c \in Z(M)$.

Proof:

For all $\mathrm{x} \in \mathrm{M}$ and $\delta \in \Gamma$, we have

$\psi(\mathrm{x}) \delta \mathrm{c}=\mathrm{c} \delta \mathrm{x}$,

Then, $(\mathrm{a} \alpha \mathrm{x} \beta \mathrm{b}) \delta \mathrm{c}=\mathrm{c} \delta \mathrm{x}$

Replacing $\mathrm{x}$ by $\mathrm{x} \lambda \mathrm{y}$ in (2), and using (2), we get

$\operatorname{a\alpha x} \beta[\mathrm{b} \delta \mathrm{c}, \mathrm{y}]_{\lambda}=0$, for all $\mathrm{x}, \mathrm{y} \in \mathrm{M}$ and $\alpha, \beta, \delta \in \Gamma$ 
Replacing $\mathrm{x}$ by $c \delta \mathrm{x} \lambda \mathrm{y}$ in (3), other hand replacing $\mathrm{x}$ by $c \delta \mathrm{x}$ in (3) with left multiplying by $\mathrm{y}$,and subtracting two equations, we obtain

$[\mathrm{a} \delta \mathrm{c}, \mathrm{y}]_{\lambda} \alpha \mathrm{x} \beta[\mathrm{b} \delta \mathrm{c}, \mathrm{y}]_{\lambda}=0$, for all $\mathrm{x}, \mathrm{y} \in \mathrm{M}$ and $\alpha, \beta, \delta, \lambda \in \Gamma$

Since $M$ is a prime, for all $x \in M$, we get

$[\mathrm{a} \delta \mathrm{c}, \mathrm{y}]_{\lambda}=0$ or $[\mathrm{b} \delta \mathrm{c}, \mathrm{y}]_{\lambda}=0$.

That means either a $\alpha c \in Z(M)$ or $b \alpha c \in Z(M)$.

\section{Theorem (2.6):}

Let $\mathrm{M}$ be a 2-torsion free prime $\Gamma$-near ring , and $F_{1}$ and $F_{2}$ are two generalized $\Gamma$ - derivations on $M$ associated with $\Gamma$-derivations $D_{1}$ and $D_{2}$ respectively, then the mapping $\psi(x)$ is free action, for all $x \in M$, when:

1) $\psi(x)=D_{1}(x)+D_{2}(x)$

2) $\psi(x)=D_{1}^{2}(x)+D_{2}(x)$

3) $\psi(x)=D_{1}(x)+D_{2}^{2}(x)$

4) $\psi(x)=F_{i}(x)+D_{i}^{2}(x)$, for all $i=1,2$.

5) $\psi(x)=F_{1}^{2}(x)+F_{2}(x)$

6) $\psi(x)=F_{1}(x)+F_{2}^{2}(x)$.

Proof:

We will prove (4). The proof of other results is by the same way.

Let $\mathrm{i}=2$, for all $\mathrm{x} \in \mathrm{M}$, we have

$\psi(\mathrm{x})=\mathrm{F}_{2}(\mathrm{x})+\mathrm{D}_{2}^{2}(\mathrm{x})$.

Let $\mathrm{a} \in \mathrm{D}^{*}(\psi)$, then $\psi(\mathrm{x}) \alpha \mathrm{a}=\mathrm{a} \alpha \mathrm{x}$, for all $\mathrm{x} \in \mathrm{M}$ and $\alpha \in \Gamma$.

That is

$\mathrm{a} \alpha \mathrm{x}=\mathrm{F}_{2}(\mathrm{x}) \alpha \mathrm{a}+\mathrm{D}_{2}^{2}(\mathrm{x}) \alpha \mathrm{a}$, for all $\mathrm{x} \in \mathrm{M}$ and $\alpha \in \Gamma$

Putting $\mathrm{x} \beta$ a for $\mathrm{x}$ in (1), and using (1), we get

$\mathrm{a} \alpha x \beta \mathrm{a}=2 \mathrm{D}_{2}(\mathrm{x}) \beta \mathrm{D}_{2}(\mathrm{a}) \alpha \mathrm{a}+\mathrm{x} \beta \mathrm{D}_{2}(\mathrm{a}) \alpha \mathrm{a}+\mathrm{x} \beta \mathrm{D}_{2}^{2}(\mathrm{a}) \alpha \mathrm{a}$

Replacing $\mathrm{x}$ by $\mathrm{y} \delta \mathrm{x}$ in (2), and using (2), we get:

$2\left(\mathrm{D}(\mathrm{y}) \delta \mathrm{x} \beta \mathrm{D}_{2}(\mathrm{a}) \alpha \mathrm{a}=0\right.$,

Since $M$ is 2-torsion free, we have

$\mathrm{D}_{2}(\mathrm{y}) \delta \mathrm{x} \beta \mathrm{D}_{2}$ (a) $\alpha \mathrm{a}=0$, for all $\mathrm{x}, \mathrm{y} \in \mathrm{M}$ and $\alpha, \beta, \delta \in \Gamma$

Putting $\mathrm{z}$ for $\mathrm{D}_{2}(\mathrm{a})$ in (3), we get

$\mathrm{D}_{2}(\mathrm{y}) \delta \mathrm{x} \beta \mathrm{z} \alpha \mathrm{a}=0$, for all $\mathrm{x}, \mathrm{y}, \mathrm{z} \in \mathrm{M}$ and $\alpha, \beta, \delta \in \Gamma$

Replacying $x \beta z$ by $r$, we get

$\mathrm{D}_{2}(\mathrm{y}) \delta \mathrm{r} \alpha \mathrm{a}=0$, for all $\mathrm{y}, \mathrm{r} \in \mathrm{M}$ and $\alpha, \delta \in \Gamma$

Since $M$ is prime and $\mathrm{D} \neq 0$, we get $\mathrm{a}=0$, that's mean our mapping is a free action.

Theorem (2.7):

Let $\mathrm{M}$ be a semi prime $\Gamma$-near ring, and let $\mathrm{T}$ be a centralizer, $\mathrm{F}$ be a generalized $\Gamma$-derivation with associated $\Gamma$-derivation $\mathrm{D}$. If $\mathrm{a}$ is dependent element of $\mathrm{D}, \mathrm{a} \in \mathrm{M}$, then $\psi=(\mathrm{F} \circ \mathrm{T})$ is a free action.

\section{Proof:}

Let $\psi=(\mathrm{F} \circ \mathrm{T})$, and $\mathrm{a} \in \mathrm{D} *(\psi)$, then $\psi(\mathrm{x}) \alpha \mathrm{a}=\mathrm{a} \alpha \mathrm{x}$, for all $\mathrm{x} \in \mathrm{M}$ and $\alpha \in \Gamma$, That is

$(\mathrm{FoT})(\mathrm{x}) \alpha \mathrm{a}=\mathrm{a} \alpha \mathrm{x}$,

Replacing $\mathrm{x}$ by $\mathrm{x} \beta \mathrm{y}$ in (1), and using (1), we get

$(\mathrm{F} \circ \mathrm{T})(\mathrm{x})[\mathrm{a}, \mathrm{y}]_{\alpha}=\mathrm{T}(\mathrm{x}) \beta \mathrm{D}(\mathrm{y}) \alpha \mathrm{a}$, for all $\mathrm{x}, \mathrm{y} \in \mathrm{M}$ and $\alpha, \beta \in \Gamma$

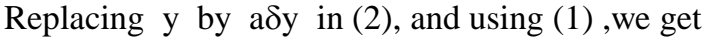

$\mathrm{a} \beta \mathrm{x} \delta[\mathrm{a}, \mathrm{y}]_{\alpha}=\mathrm{T}(\mathrm{x}) \beta \mathrm{D}(\mathrm{a}) \delta \mathrm{y} \alpha \mathrm{a}+\mathrm{T}(\mathrm{x}) \beta \mathrm{a} \delta \mathrm{D}(\mathrm{y}) \alpha \mathrm{a}$, for all $\mathrm{x}, \mathrm{y} \in \mathrm{M}$ and $\alpha, \beta, \delta \in \Gamma$

Multiplying (3) on the left by $z$, other hand replacing $x$ by zax in (3) and Subtracting two equations, we get $[\mathrm{a}, \mathrm{z}]_{\alpha} \beta \mathrm{x} \delta[\mathrm{a}, \mathrm{z}]_{\alpha}=0$,for all $\mathrm{x}, \mathrm{z} \in \mathrm{M}$ and $\alpha, \beta, \delta \in \Gamma$

Replacing $\mathrm{z}$ by y in (4), we get:

$[\mathrm{a}, \mathrm{y}]_{\alpha} \beta \mathrm{x} \delta[\mathrm{a}, \mathrm{y}]_{\alpha}=0$, which by semiprimeness of $\mathrm{M}$, implies 
$[\mathrm{a}, \mathrm{y}]_{\alpha}=0$, for all $\mathrm{y} \in \mathrm{M}, \alpha \in \Gamma$

Substitute (5) in (2), and by the hypothesis, we get

$\mathrm{T}(\mathrm{x}) \beta \mathrm{a} \alpha \mathrm{y}=0$, for all $\mathrm{x}, \mathrm{y} \in \mathrm{M}$ and $\alpha, \beta \in \Gamma$

Replacying y by $\mathrm{y} \delta \mathrm{T}(\mathrm{x}) \beta \mathrm{a}$ in (6), and using semiprimeness of $\mathrm{M}$, we get

$\mathrm{T}(\mathrm{x}) \beta \mathrm{a}=0$, for all $\mathrm{x} \in \mathrm{M}, \beta \in \Gamma$

Taking $\mathrm{F}$ of (7), and using (3) and (1),we get

$\mathrm{a} \alpha \mathrm{x} \beta \mathrm{a}=0$, for all $\mathrm{x} \in \mathrm{M}$ and $\alpha, \beta \in \Gamma$

Since $\mathrm{M}$ is semi prime, we get $\mathrm{a}=0$, which implies that $(\mathrm{F} \circ \mathrm{T})$ is a free action.

\section{Theorem (2.8):}

Let $\mathrm{T}$ be a reverse centralizer of $\Gamma$-near ring $\mathrm{M}$. Then $\psi: \mathrm{M} \rightarrow \mathrm{M}$ which defined by $\psi(\mathrm{x})=[\mathrm{T}(\mathrm{x}), \mathrm{x}]_{\alpha}$, for all $\mathrm{x} \in \mathrm{M}$ and $\alpha \in \Gamma$ is a free action.

Proof:

That is

Let $\mathrm{a} \in \mathrm{D}^{*}(\psi)$, then $\psi(\mathrm{x}) \beta \mathrm{a}=\mathrm{a} \beta \mathrm{x}$, for all $\mathrm{x} \in \mathrm{M}$ and $\alpha, \beta \in \Gamma$

$[\mathrm{T}(\mathrm{x}), \mathrm{x}]_{\alpha} \beta \mathrm{a}=\mathrm{a} \beta \mathrm{x}$, for all $\mathrm{x} \in \mathrm{M}$ and $\alpha, \beta \in \Gamma$

Linearizing (1) , and using (1), we get:

$[\mathrm{T}(\mathrm{x}), \mathrm{y}]_{\alpha} \beta \mathrm{a}+[\mathrm{T}(\mathrm{y}), \mathrm{x}]_{\alpha} \beta \mathrm{a}=0$, for all $\mathrm{x}, \mathrm{y} \in \mathrm{M}$ and $\alpha, \beta \in \Gamma$

Replacing y by ady in (2), and using (2),we get

$-\mathrm{a} \delta[\mathrm{T}(\mathrm{y}), \mathrm{x}]_{\alpha} \beta \mathrm{a}+[\mathrm{T}(\mathrm{x}), \mathrm{a}]_{\alpha} \delta \mathrm{y} \beta \mathrm{a}+\mathrm{T}(\mathrm{y}) \delta[\mathrm{a}, \mathrm{x}]_{\alpha} \beta \mathrm{a}+[\mathrm{T}(\mathrm{y}), \mathrm{x}]_{\alpha} \delta \mathrm{a} \beta \mathrm{a}=0$, for all $\mathrm{x}, \mathrm{y} \in \mathrm{M}$ and $\alpha, \beta, \delta \in \Gamma$

Replacing $\mathrm{y}$ and $\mathrm{x}$ by $\mathrm{a}$ in (3), and other hand replacing $\mathrm{x}$ by $\mathrm{a}$ in (3), and using them, we get

$-a \delta a \beta a+a \delta a \beta a+a \delta a \beta a=0$

That is, $a \delta a \beta a=0$, we get $a=0$. Hence $\psi$ is free action.

\section{References}

[1]. A.Laradji and A.B.Thaheem, On Dependent Elements in Semiprime Ring, Math.Japonica, 47 (1998), No.1, 576-584. F. J. Murray and von Neumann J., On Rings of Operators, , 37, 116-229, Ann. Math.,(1936).

[2]. M. S. Samman and Anwar M., Dependent Element of Left Centralizer of Semiprime Rings, 33, 313-319, The Arabian Journal for Science and Engineering (2008)

[3]. J.Vakman, On Dependent Elements and Related Problems In Ring, Internationsl Math. Journal, 8 (2005), No.2, 93-112.

[4]. J.Vakman, Free Actions of Semiprime Rings with Involution Induced by Aderivation, Demenstratio Mathematica, 38 (2006), No.4, 811-817.

[5]. J.Vakman and I.Kosi-UIbI, On Dependent Elements in Rings, International Mathematical Journal, 6 (2005), No.2, 93-112.

[6]. J.Vakman, I.Kosi-UIbI, Centralizer on Ring and Algebras, Bull, Austral.Math.Soc, 71, (2005), 234-255.

[7]. J.Vukman and Ireana, On Dependent Elements in Rings, 54, 2895-2906, IJMMS,(2004). 